\title{
Enhancing synergies in nature's contributions to people in socio-ecological production landscapes and seascapes: lessons learnt from ten site-based projects in biodiversity hotspots
}

\author{
Yasuo Takahashi ${ }^{1}$ (1) $\cdot$ Kylie J. Park ${ }^{2} \cdot$ Yoji Natori ${ }^{3,4} \cdot$ Devon Dublin $^{3,5} \cdot$ Rajarshi Dasgupta $^{1} \cdot$ Koji Miwa $^{1}$
}

Received: 17 August 2020 / Accepted: 4 February 2021 / Published online: 1 March 2021

(c) The Author(s) 2021

\begin{abstract}
Trade-offs in nature's contributions to people (NCP), particularly in material NCP versus regulating and non-material NCP, continue to rise. Socio-ecological production landscapes and seascapes (SEPLS) represent harmonious human-nature interactions resulting in positive outcomes for both biodiversity and human well-being, thus implying synergies among multiple NCP are possible. In case studies of ten projects selected from biodiversity hotspots under the GEF-Satoyama Project, we investigated whether and how synergies in NCP exist within SEPLS and explored management interventions that enhanced these synergies. Using the responses to an online survey completed by project managers from each project and drawing on project reports, we identified a wide array of NCP deriving from various ecosystems within the project SEPLS. Habitat and food provisions, both attributed to multiple ecosystem types, were key components of the NCP bundles present in the project SEPLS. Among the management options that enhanced NCP in SEPLS were food-centred approaches entailing organic agriculture, eco-labelling, branding and improved agricultural practices. Habitat-centred approaches included participatory biodiversity monitoring, ecosystem restoration, co-management and conservation agreements with landowners. Synergies in NCP were generated by integrating these interventions with enabling governance structures and through community empowerment. If combined with mapping and modelling techniques, identifying NCP bundles in SEPLS from local people's perspectives as we outlined in this study, would help to better contextualise the analysis of NCP bundles. Such contextualised NCP bundle analyses will help field practitioners understand how to enhance synergies between multiple NCP and the broader conservation community could access untapped NCP knowledge.
\end{abstract}

Keywords Ecosystem services $\cdot$ Equality $\cdot$ Landscape approach $\cdot$ Impact evaluation $\cdot$ Satoyama $\cdot$ Satoumi

\section{Introduction}

Handled by Shizuka Hashimoto, University of Tokyo, Japan.

Yasuo Takahashi

yasuo.takahashi@iges.or.jp

1 Institute for Global Environmental Strategies, 2108-11, Kamiyamaguchi, Hayama, Kanagawa 240-0115, Japan

2 Tonkin \& Taylor Limited, Victoria Street West, PO Box 5271, Auckland 1142, New Zealand

3 Conservation International Japan, MEISTER YOTSUYA 201, 1-17 Yotsuya, Shinjuku, Tokyo 160-0004, Japan

4 Present Address: Akita International University, Yuwa, Akita, Akita 010-1292, Japan

5 Present Address: Hokkaido University of Education, 1-15-55 Shiroyama, Kushiro, Hokkaido 085-8580, Japan
Biodiversity underpins human well-being (Díaz et al. 2019). But ironically, the biodiversity goal is often incompatible with the immediate human well-being goals on the earth where humans play an increasingly dominant role (McShane et al. 2011). This is interpreted as tradeoffs in the benefits that biodiversity provides to people. These benefits are known as ecosystem services (ES) and occur between different ES types, across space and time and among people (Rodríguez et al. 2006). Over the past 50 years, humans have increased the production of food, materials and energy on the terrestrial surfaces of the earth, while faced with a rapid decline in almost all other ES (Díaz et al. 2019). Likewise, the literature analysing 
ES bundles (collections of different types of ESs within a clearly defined area deriving from land and sea) at different spatial scales commonly identify trade-offs between provisioning ES and regulating, cultural or supporting ES (Raudsepp-Hearne et al. 2010; Maes et al. 2012; Turner et al. 2014; Yang et al. 2015; Renard et al. 2015; Dittrich et al. 2017). Such trade-offs are more prominent at smaller spatial scales (Yang et al. 2015; Dittrich et al. 2017). ES trade-offs over time occur when ES management aims to meet the short-term needs of society but does not consider its future consequences (Rodríguez et al. 2006). This is well exemplified by intensified agriculture that increases yield in the short term but leads to soil quality loss and thus to yield loss in the long term. These trade-offs affect people in different groups in different ways, exacerbating inequalities that are already prevalent across the world (Daw et al. 2011). Given the prevalence of trade-offs in ES, the efforts towards the 2050 global biodiversity vision "Living in harmony with nature" requires deliberate management of these trade-offs (Howe et al. 2014).

Socio-ecological production landscapes and seascapes (SEPLS), known as 'Satoyama' and 'Satoumi', respectively, in Japanese, are "dynamic mosaics of habitats and land uses that have been shaped over the years by the interactions between people and nature in ways that maintain biodiversity and provide humans with goods and services needed for their well-being" (MOEJ and UNU-IAS 2010). Whereas trade-offs in ES are reported in many areas across the world, synergy in biodiversity conservation and human well-being is assumed in SEPLS.

Whether and how these synergies are achieved in SEPLS will be a valuable contribution to our knowledge of conservation. Whilst area-based conservation remains a primary means to conserve biodiversity, current protected areas insufficiently cover the areas of biological importance, and the gap is further increasing due to many species shifting their habitat ranges with climate change (IPBES et al. 2019). Noting this, the Post-2020 Global Biodiversity Framework (SCBD 2020) is considering ambitious targets for expanding and strengthening protected area networks and other effective area-based conservation measures (OECMs). Such areas should go beyond the limited land and sea surfaces of the globe set aside primarily for biodiversity, and extend into production lands and seas. Areas in the IUCN's protected area categories V "protected landscape/seascape" and VI "protected areas which conserve ecosystems and habitats, together with associated cultural values and traditional natural resource management systems" (Dudley 2008), as well as the OECMs (CBD 2018), would be the first candidate for such additional efforts. SEPLS demonstrate the harmonious human-nature interactions envisaged for these areas. Thus, understanding the synergies among various ESs in SEPLS and the options to manage the trade-offs will help accelerate conservation efforts in such areas, thereby safeguarding global biodiversity.

The GEF-Satoyama Project (http://www.thegef.org/proje cts) worked with ten sub-grant projects in biodiversity hotspots, which represent the global frontiers of highly endemic biological communities under accelerating anthropogenic threats (Myers et al. 2000). By gathering data on the SEPLS represented by these sub-grant projects, this study aims to investigate whether and how synergies in ES exist in SEPLS; and to explore the options to effectively manage trade-offs in ES in SEPLS. In so doing, we used the nature's contributions to people (NCP) framework (Díaz et al. 2018). The NCP framework builds on the ES framework (Millennium Ecosystem Assessment 2005) and is considered to better represent a wider variety of perspectives on human-nature interactions including those from the social sciences or held by indigenous peoples and local communities (Díaz et al. 2018). For the purposes of this study, the eighteen explicitly defined NCP categories were suitable for understanding the diverse values associated with the project SEPLS.

\section{Materials and methods}

\section{Overview of the GEF-Satoyama Project and data gathering}

Of the ten project sites under the GEF-Satoyama Project, three were in Indo-Burma, three in Tropical Andes and four in Madagascar and the Indian Ocean Islands biodiversity hotspots (Table 1 and Fig. 1). They were selected from 130 applications received from 16 countries within these biodiversity hotspots based on predetermined selection criteria (Supplementary Appendix 1).

For each of the ten project sites, we used an online survey and regular project reports to gather data about the ecosystems and important species present, the NCP recognized by the community, and the management interventions and their effects on NCP.

To acquire baseline information in the initial implementation stage of the individual projects, the project managers of each project site acting as focal persons, completed the online survey (see Supplementary Appendix 2 for the survey form). This is because they were in an opportune position to obtain the required information from relevant stakeholders and knowledge holders within the project site. Online surveys have been used for evaluating preferences for different NCP or ecosystem services, particularly cultural services, by NCP users (Darvill and Lindo 2016; Hermes et al. 2018; Santos-Martín et al. 2019). It was not feasible, however, in our study to conduct an online survey directly with the NCP users, i.e., the local people in the project sites, as they mostly had limited internet access 
Table 1 Overview of the ten sub-grant projects

\begin{tabular}{|c|c|c|c|}
\hline Code $^{\mathrm{a}}$ & Project full title & Sub-grantee name & Location \\
\hline \multicolumn{4}{|c|}{ Indo-Burma biodiversity hotspot } \\
\hline IN & $\begin{array}{l}\text { Mainstreaming Community-Conserved } \\
\text { Areas for Biodiversity Conservation in } \\
\text { Nagaland }\end{array}$ & The Energy and Resources Institute (TERI) & Nagaland, India \\
\hline MM & $\begin{array}{l}\text { Conservation and sustainable use of fresh- } \\
\text { water ecosystems in Myanmar }\end{array}$ & Fauna \& Flora International (FFI) & Kachin State, Tanintharyi Region, Myanmar \\
\hline $\mathrm{TH}$ & $\begin{array}{l}\text { Promoting and Enhancing the Karen } \\
\text { Indigenous Sustainable Socio-ecological } \\
\text { Production System in Northern Thailand }\end{array}$ & $\begin{array}{l}\text { Inter Mountain Peoples' Education and Cul- } \\
\text { ture in Thailand Association (IMPECT) }\end{array}$ & Chiang Mai, Thailand \\
\hline \multicolumn{4}{|c|}{ Madagascar and Indian Ocean Islands biodiversity hotspot } \\
\hline $\mathrm{KM}$ & $\begin{array}{l}\text { A landscape management model for con- } \\
\text { serving biodiversity in the Comoro Islands }\end{array}$ & Dahari & Anjouan Island, Comoros \\
\hline MU & $\begin{array}{l}\text { Mainstreaming the Contribution of coastal } \\
\text { wetlands biodiversity for Sustainable Eco- } \\
\text { nomic \& Livelihood Development at Cité } \\
\text { La Chaux 'Barachois', Mahébourg }\end{array}$ & $\begin{array}{l}\text { Environmental Protection and Conservation } \\
\text { Organisation (EPCO) }\end{array}$ & Mahébourg, Mauritius \\
\hline MG & $\begin{array}{l}\text { Integrated adaptive management to protect } \\
\text { ecological integrity in the Socio-Ecolog- } \\
\text { ical Production Landscape (SEPL) of the } \\
\text { south-east watershed of Makira Natural } \\
\text { Park }\end{array}$ & Wildlife Conservation Society (WCS) & Analanjirofo, Madagascar \\
\hline $\mathrm{SC}$ & $\begin{array}{l}\text { The development of a co-management } \\
\text { plan, designed by fishers, to minimise the } \\
\text { impact of the Seychelles artisanal fishery } \\
\text { on threatened species }\end{array}$ & Green Islands Foundation (GIF) & Mahé Plateau, Seychelles \\
\hline \multicolumn{4}{|c|}{ Tropical Andes biodiversity hotspot } \\
\hline $\mathrm{CO}$ & $\begin{array}{l}\text { Reconciling biodiversity conservation and } \\
\text { agricultural production in agroforestry } \\
\text { cultivation systems in the Colombian } \\
\text { Andes: a model for Colombia's post- } \\
\text { conflict era }\end{array}$ & Universidad Industrial de Santander (UIS) & San Vicente de Chucurí, Colombia \\
\hline EC & $\begin{array}{l}\text { Improvement of the livelihoods of the } \\
\text { communities through the sustainable } \\
\text { management of productive landscapes and } \\
\text { biodiversity conservation in mangrove, the } \\
\text { dry forest and rainforest }\end{array}$ & $\begin{array}{l}\text { Fundación para la Investigación y Desar- } \\
\text { rollo Social (FIDES) }\end{array}$ & Manabí and Esmeraldas, Ecuador \\
\hline PE & $\begin{array}{l}\text { Consolidation of the participatory manage- } \\
\text { ment of the Alto Huayabamba Conserva- } \\
\text { tion and strengthening of partnerships for } \\
\text { conservation, production and research in } \\
\text { the Peruvian Amazon }\end{array}$ & Amazónicos por la Amazonía (AMPA) & Bolívar, Peru \\
\hline
\end{tabular}

${ }^{\text {a }}$ Code is a two-letter acronym of the country name which refers to each of the ten sub-grant projects consistently throughout this article. Find more details on the sub-grant projects in the GEF-Satoyama Project website: http://gef-satoyama.net/subgrantprojects/

and capability in completing an online survey. We thus requested the project managers to respond to the survey in a way that comprehensively captured the views of local people in the project site. We extracted responses to the survey questions on the major ecosystem types and species identified as being present in the project SEPLS and the NCP associated with those ecosystems and species, as recognized by the local people (per Díaz et al. 2018). The respondents rated the importance to the local people of each NCP associated with each ecosystem type and each species on a five-point Likert Scale, where 5 was of critical importance and 1 was of minor importance. Hereafter we refer to this score as the 'respondent NCP score'.

We extracted data on the effects of the project interventions on NCP from the projects' annual report from the final project year and the project final report written by the project focal persons. These reports contained information on the major project activities and their progress indicators stipulated during project appraisal, as well as their major achievements by the project end as assessed against the project-specific indicators. 


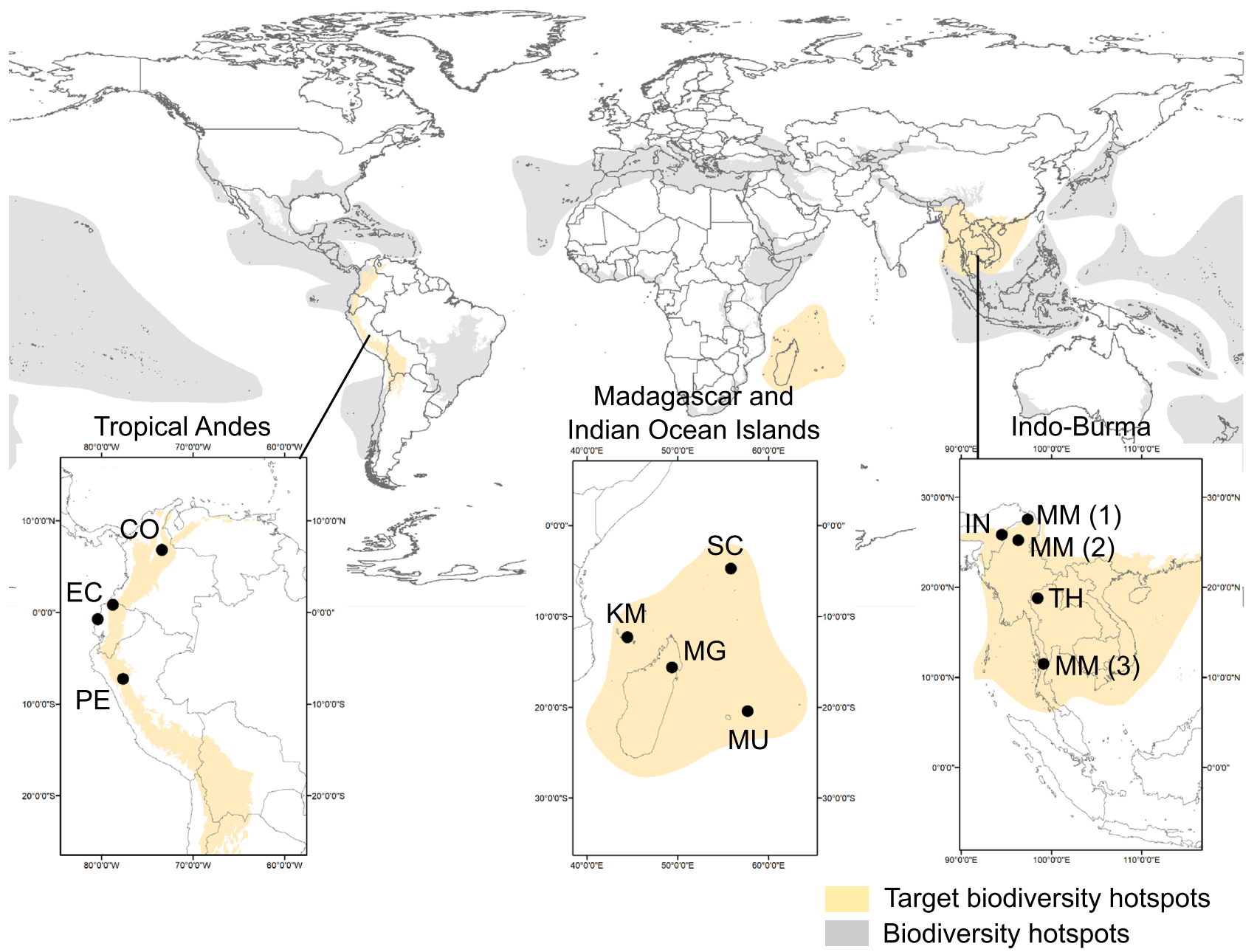

Fig. 1 The GEF-Satoyama Project sub-grant project site map. Note: the two-letter acronyms aside the dots indicating the respective project site locations are the project codes explained in Table 1

We brought together data extracted from these sources and validated them by cross-referencing other reports and materials submitted by the projects, and with observations made during annual site visits.

\section{Analysis}

To identify the full suite of important NCP derived from each ecosystem type within a project SEPLS, we compiled an "ecosystem-NCP" scores using the respondent NCP importance scores directly and indirectly associated with each ecosystem type in that project site. Using the data retrieved from the online survey, we first identified the respondent NCP scores directly attributed to each ecosystem type within the project site. For each ecosystem type, we then used the respondent NCP score for each species associated with that ecosystem type to identify additional NCP that may not have been directly assigned to that ecosystem type by the respondents. If the NCP had been assigned by the respondent to both the ecosystem type and the species found in that ecosystem, we used the highest respondent NCP of the two. In addition, we interpreted the presence of an important species within a given ecosystem as that ecosystem being important for NCP 1 (habitat creation and maintenance). The NCP 1 score for a given ecosystem type was derived from the highest respondent NCP importance score for any species identified in that ecosystem. See Supplementary Appendix 4 for a more detailed explanation and a worked example of the procedure used to compile ecosystem-NCP scores for a given ecosystem type. This procedure double-counts NCP but is logically correct considering how the NCP categories are determined (Díaz et al. 2018) and how NCP cascade from another (Haines-Young and Potschin 2010). We applied this procedure to more explicitly recognize the importance of species as sources of NCP, and of the ecosystems in providing habitats to these species. 


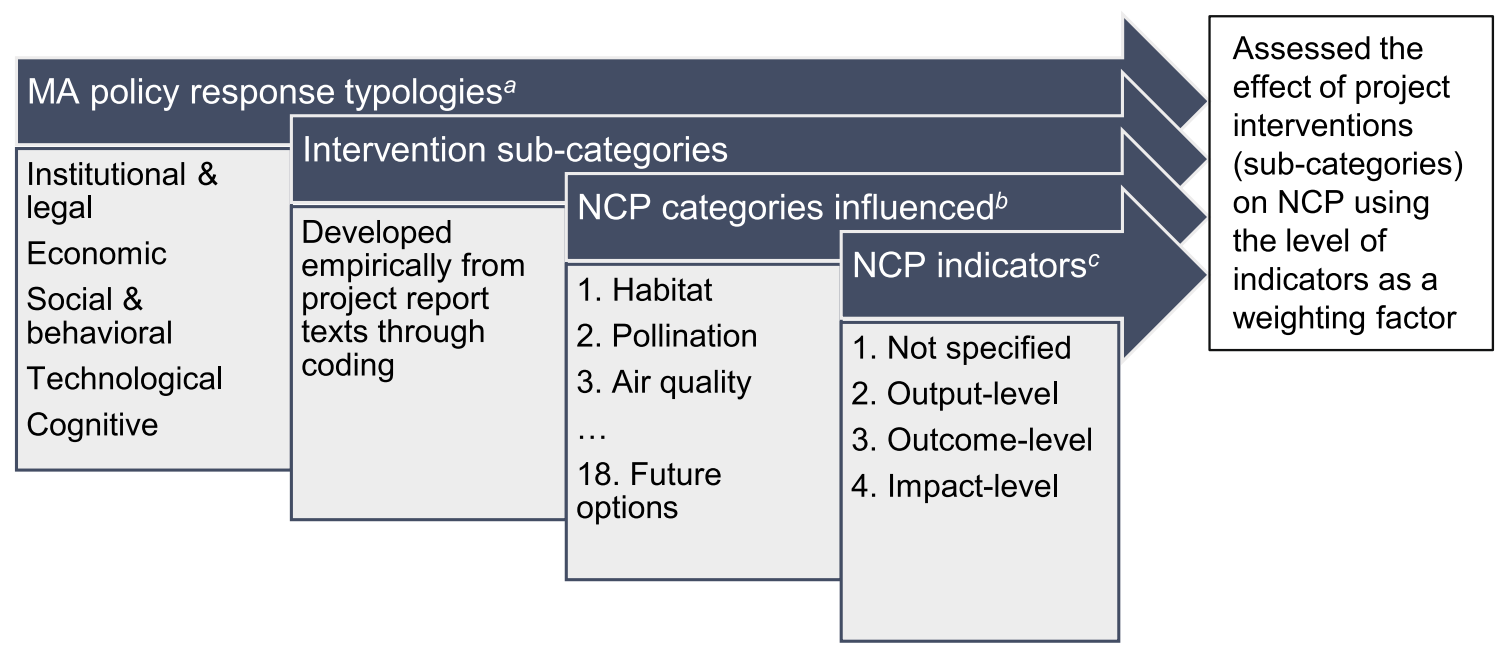

Fig. 2 Steps taken to assess the effect of project interventions on NCP. ${ }^{\text {a }}$ Refer to MA (2005) for the detailed accounts for the policy response typologies. ${ }^{b}$ Refer to Díaz et al. (2018) for the NCP categories. ${ }^{c}$ The level of indicators were specified referring to the program logic model (OECD 2002). An output-level indicator represented the immediate results of an intervention, including goods and services directly produced by a project. An outcome-level indicator rep-

We assessed the effects of different project interventions on NCP through a four-step analysis (Fig. 2), mainly using the data extracted from the project annual and final reports. From these reports, we identified major project interventions that aimed to or resulted in safeguarding or enhancing NCP. We categorized these interventions first by five policy response typologies adopted by the Millennium Ecosystem Assessment (MA 2005), i.e., institutional and legal; economic; social and behavioural; technological; and cognitive responses. These typologies represent the primary intention and mechanism through which different interventions curb anthropogenic threats to nature. We further grouped the project interventions into sub-categories that we developed empirically through the coding of information provided in the project reports to more concretely explain the type of interventions commonly implemented by the projects. Thereafter, we identified one or more NCP that each project intervention influenced. We used the detailed account of the NCP categories in Díaz et al. (2018) to unambiguously identify the NCP that the interventions influenced, and used our expert judgement based on our knowledge of the project activities.

On that basis, we identified an indicator from the project reports that best represented each of the NCP influenced by project interventions. We then classified the indicators into three types, i.e., output-, outcome- or impact-level indicators in accordance with the program logic model (OECD 2002; Mascia et al. 2014). The annual report template did require each project to report its progress against the outcome indicators that are specific and appropriate to the respective resented "the desired ends that intervention outputs are intended to induce", such as changes in knowledge, attitudes, behaviours or social and environmental conditions leading to safeguarding or enhancing NCP. We defined impact-level indicators as the variables that directly gauge the changes in quantity or quality of NCP following the project intervention

project. However, we needed to apply this re-classification of indicators to standardize the level of influence for the purpose of this study, which requires all ten projects to be compared on the same stage. We assigned the indicators a weighting factor: 1 for the effects recognized but without any indicator; 2 for the effect with an output-level indicator; 3 with an outcome-level indicator; and 4 with an impact-level indicator. We used this weighting score to measure the relative magnitude of the effect of different project interventions on NCP.

\section{Results}

\section{Multiplicity of NCP in SEPLS}

The online survey results identified a wide array of NCP attributed to the project SEPLS (Fig. 3). Food and feed (NCP 12), among other NCP categories, had the highest total score (84). Habitat creation and maintenance (NCP 1) scored the second (78), including the provision of habitats to a total of 29 globally threatened species (Table 2). Learning and inspiration (NCP 15) (46) was the third highest scoring, followed by regulation of freshwater quantity, location and timing (NCP 6) (40) and pollination and dispersal of seeds and other propagules (NCP 2) (31). In addition, 23 out of the 29 globally threatened species identified from the ten project sites were found to provide important contributions to people, particularly pollination and seed dispersal (NCP 


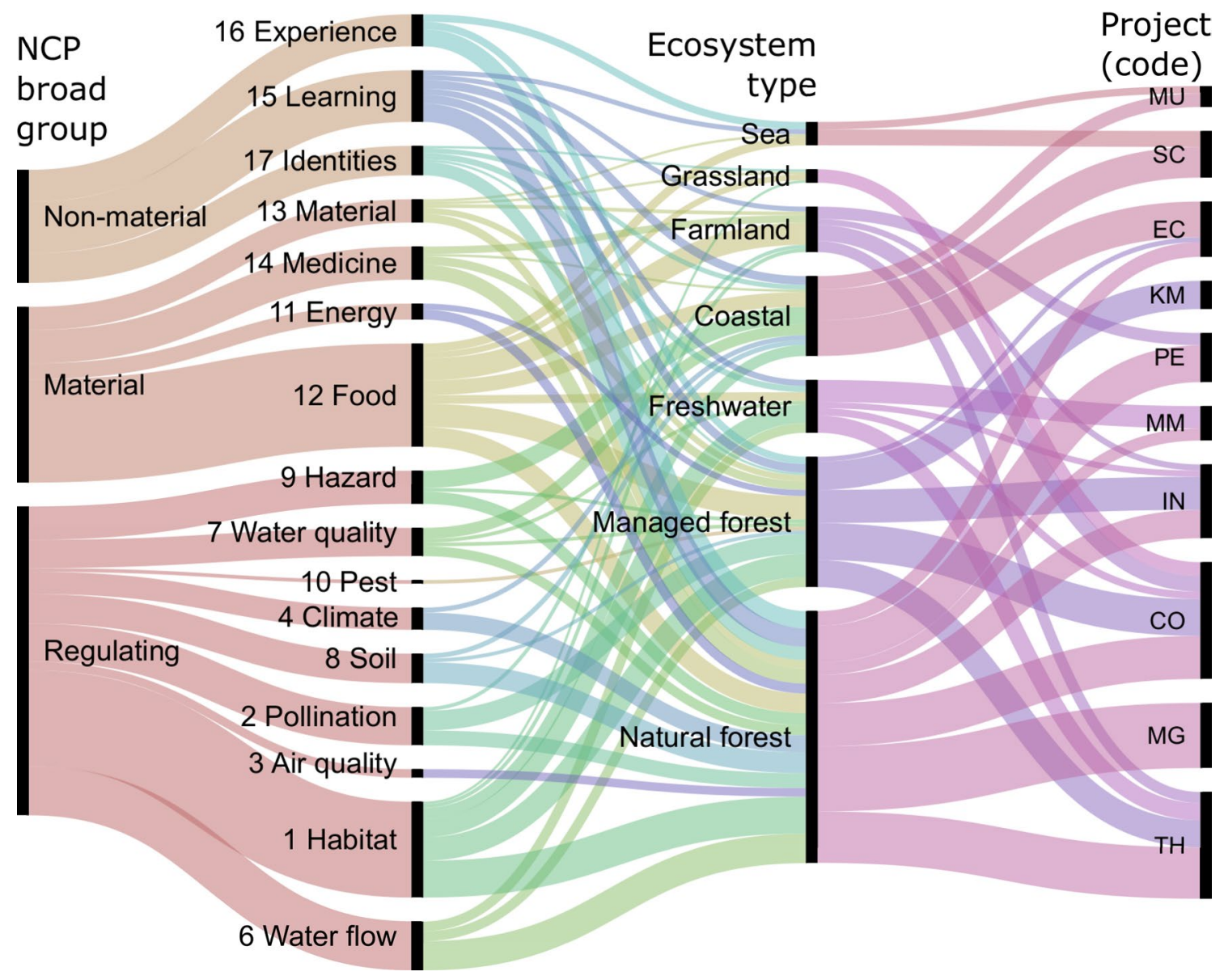

Fig. 3 NCP derived from different ecosystems identified in the ten project sites. Rawgraphs (Mauri et al. 2017) generated the alluvial diagram using the aggregated NCP importance scores attributed to different ecosystem types identified in the ten project sites. The width of the horizontal bands explains the relative importance of the NCP reporting category, which is the sum of the NCP importance score

\section{2; 9 species), food (NCP 12; 7 species) and learning (NCP} 15; 5 species) (Table 2).

Each project site comprised a collection of multiple ecosystem types with two exceptions (MG, KM), and different sets of NCP were attributed to different ecosystem types (Fig. 3). Natural forest was highly valued for the regulating contributions it provided, particularly habitats (NCP 1) and freshwater flow regulation (NCP 6). Managed forest and coastal ecosystems were recognised as important for their regulating and material contributions. In particular, managed forest provided habitat (NCP 1), pollination (NCP 2) and food (NCP 12). Coastal systems, especially mangroves, were recognised as important for regulating hazards and extreme events (NCP 9) and providing food (NCP 12). Farmland was primarily valued for its role in providing food (NCP 12). Highly diverse NCP were derived from heterogeneous landscapes and seascapes made up of multiple ecosystem types. across the ten projects. Categories were ordered in a way to minimize the number of crossing bands. NCP broad groups and reporting categories are presented in short. Please refer to Díaz et al. (2018) for their full descriptions. 'Project' labels show project codes. Refer to Table 1 for the full project titles

\section{Project effects on NCP}

We identified 15 different types of interventions implemented by the ten projects which encompassed the MA's five policy response typologies (Fig. 4). Technological responses were used by eight projects and entailed ecosystem restoration, organic agriculture, improved agricultural practices, sustainable use of non-timber forest products (NTFPs) and ecotourism. Cognitive responses were used by seven projects and included participatory biodiversity monitoring, the documentation of traditional knowledge and participatory GIS mapping. Social and behavioural responses were used by five projects and included the establishment of inclusive community-based organizations (CBOs), capacity building, reinforcement of customary law and knowledge exchange. Economic responses were adopted by four projects and entailed eco-labelling, branding and conservation 
Table 2 Globally threatened species found in the ten project sites

\begin{tabular}{|c|c|c|c|c|c|}
\hline Taxon & Vernacular name & Latin name & $\mathrm{RL}^{\mathrm{a}}$ & $\mathrm{NCP}^{\mathrm{b}}$ & $\overline{\text { Project }^{\mathrm{c}}}$ \\
\hline \multirow[t]{15}{*}{ Mammal } & Indri & Indri indri & $\mathrm{CR}$ & $2,16,17$ & MG \\
\hline & Black and White Vari & Varecia variegata subcincta & $\mathrm{CR}$ & $2,16,17$ & MG \\
\hline & Silky Sifaka & Propithecus candidus & $\mathrm{CR}$ & $2,16,17$ & MG \\
\hline & Yellow-tailed woolly monkey & Oreonax flavicauda & $\mathrm{CR}$ & 2 & $\mathrm{PE}$ \\
\hline & Chinese pangolin & Manis pentadactyla & $\mathrm{CR}$ & 15 & MM \\
\hline & Livingstone's fruit bat & Pteropus livingstonii & $\mathrm{CR}$ & 2 & KM \\
\hline & Yo Hhaw (Pangolin) & Manis pentadactyla & $\mathrm{CR}$ & 14 & $\mathrm{TH}$ \\
\hline & Ecuadorian White-fronted Capuchin & Cebus aequatorialis & $\mathrm{CR}$ & 15,16 & $\mathrm{EC}$ \\
\hline & White-fronted brown lemur & Eulemur albifrons & $\mathrm{EN}$ & $2,12,16$ & MG \\
\hline & White-bellied spider monkey & Ateles belzebuth & EN & 2 & $\mathrm{PE}$ \\
\hline & Eastern Hoolock Gibbon & Hoolock leuconedys & VU & 15 & MM \\
\hline & Mangoose lemur & Eeulemur mongoz & $\mathrm{EN}$ & 2 & KM \\
\hline & Grey-bellied night monkey & Aotus lemurinus & VU & & $\mathrm{CO}$ \\
\hline & Andean night monkey & Aotus miconax & VU & 2 & $\mathrm{PE}$ \\
\hline & Spectacled bear & Tremarctos ornatus & VU & & $\mathrm{PE}$ \\
\hline \multirow[t]{6}{*}{ Bird } & White-rumped vulture & Gyps bengalensis & $\mathrm{CR}$ & 15 & MM \\
\hline & Mauritius Fody & Foudia rubra & EN & & MU \\
\hline & Perdiz santandereana & Odontophorus strophium & EN & 12,17 & $\mathrm{CO}$ \\
\hline & Anjouan scop's owl & Otus capnodes & $\mathrm{EN}$ & 10 & $\mathrm{KM}$ \\
\hline & Saurus crane & Grus antigone & VU & 15 & MM \\
\hline & Blyth's Tragopa & Tragopan blythii & VU & 16 & IN \\
\hline Reptile & Comoro ground gecko & Paroedura sanctijohannis & EN & & KM \\
\hline \multirow[t]{5}{*}{ Fish } & Napoleon wrasse & Cheilinus undulatus & EN & 12,16 & $\mathrm{SC}$ \\
\hline & Green humphead parrotfish & Bolbometopon muricatum & VU & 12,16 & $\mathrm{SC}$ \\
\hline & Great hammerhead & Sphyrna mokarran & $\mathrm{EN}$ & 12 & $\mathrm{SC}$ \\
\hline & Blacksaddled coralgrouper & Plectropomus laevis & VU & 12 & $\mathrm{SC}$ \\
\hline & Scalloped hammerhead & Sphyrna lewini & EN & 12,16 & $\mathrm{SC}$ \\
\hline \multirow[t]{2}{*}{ Plant } & Nogal & Juglans neotropica & EN & $8,12,13,14,17$ & $\mathrm{CO}$ \\
\hline & Queñual & Polylepis multijuga & VU & 13 & PE \\
\hline
\end{tabular}

${ }^{a}$ The IUCN Red List categories: CR: Critically Endangered; EN: Endangered; VU: Vulnerable, according to the IUCN Red List of Threatened Species (IUCN 2020)

${ }^{b}$ NCP 2: Pollination and dispersal of seeds and other propagules; 8: Formation, protection and decontamination of soils and sediments; 10: Regulation of detrimental organisms and biological processes; 12: Food and feed; 13: Materials, companionship and labor; 14: Medicinal, biochemical and genetic resources; 15: Learning and inspiration; 16: Physical and psychological experiences; 17: Supporting identities

c 'Project' column shows project codes. Refer to Table 1 for the project full titles

agreements. Co-management was an institutional and legal response used by four projects.

An aggregated effect of the ten projects on NCP measured by the indicators showed that, overall, they focused the most on food production (NCP 12) as well as the creation and maintenance of habitats (NCP 1) and options (NCP 18) (Fig. 4). The effects on non-material contributions, including learning and inspiration (NCP 15), experiences (NCP 16) and identities (NCP 17) were recognized by one and two indicators, respectively. Their effects on an array of regulating NCP were implied but without explicit indicators except for habitat provision (NCP 1).

Improvement in food production (NCP 12) was achieved most strongly through technological responses, including improved and organic agricultural practices adopted by six projects (See Supplementary Appendix 3 for the narratives on the causal linkage between the project interventions and their NCP outcomes). Economic responses, such as the Fair Trade and Organic certifications, were adopted by three projects.

Progress towards the maintenance of habitats (NCP 1) and future options (NCP 18) was made through cognitive, technological, legal and economic responses in particular. Participatory biodiversity monitoring was a cognitive response used by six projects. These increased scientific and stakeholder knowledge of SEPLS as being important wildlife habitats. The restoration of forest and mangroves was a technological response adopted by four projects. The use 


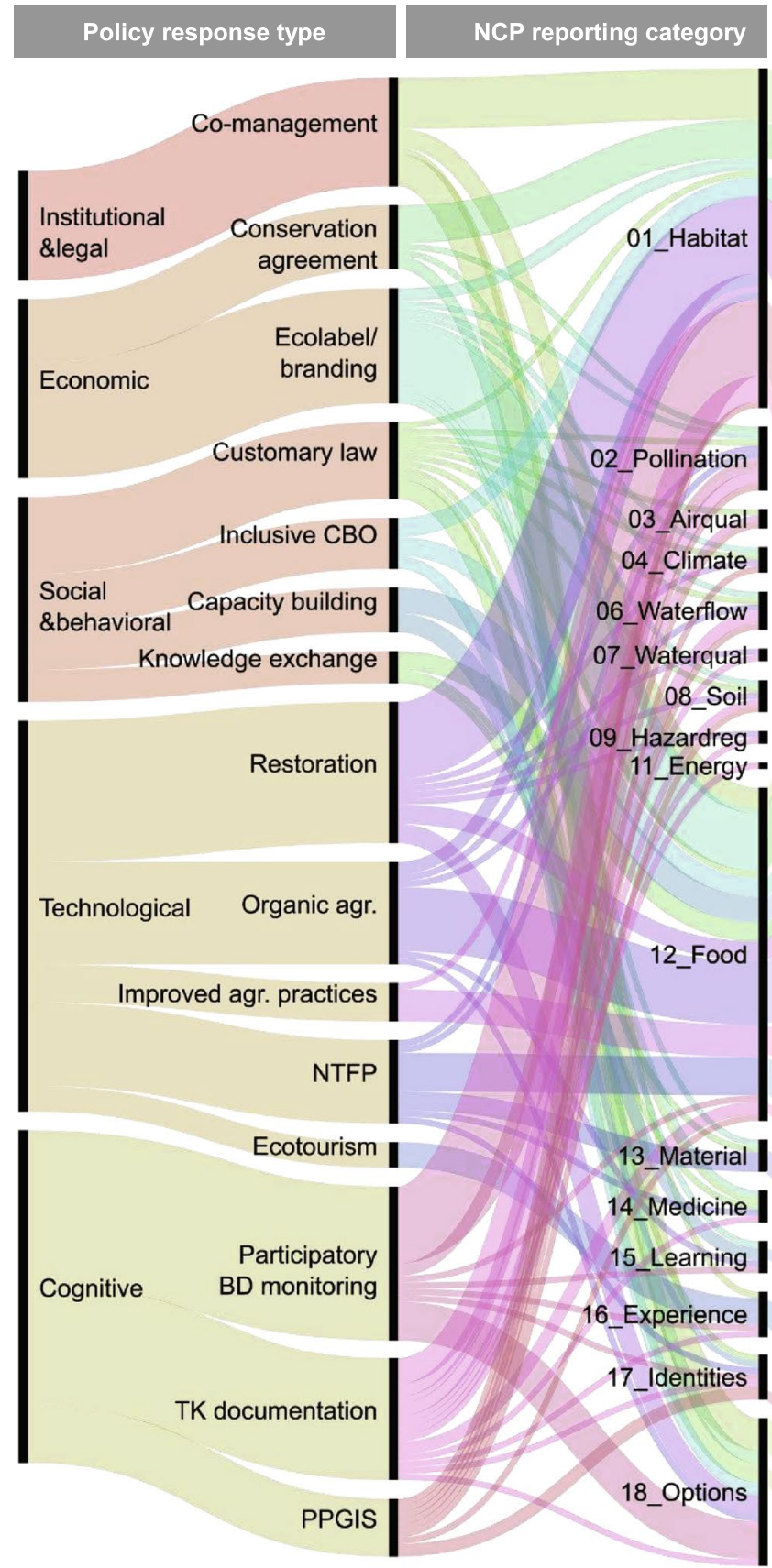

Fig. 4 Project effects on NCP and the indicators to capture the effects. Note: The alluvial diagram was developed by Rawgraphs (Mauri et al. 2017), using the aggregated weights of the effects of each project intervention on NCP from across all ten projects. The width of the horizontal crisscrossing bands indicates the aggregated significance of the effects of different policy responses on respective

of co-management schemes was an institutional and legal response adopted by five projects, where community engagement in rule making and enforcement reduced hunting and fishing which harms biodiversity and the natural resource base. The signing of conservation agreements with the

\begin{tabular}{|c|c|c|c|c|}
\hline Level & Indicator & $\begin{array}{l}\text { Value } \\
\text { (ante) }\end{array}$ & \begin{tabular}{|l} 
Value \\
(post)
\end{tabular} & Project \\
\hline++ & Area $(\mathrm{Ha})$ of zero hunting & 0 & 3751 & IN \\
\hline+++ & Average \#/km of lemur sighting & 0.05 & 0.13 & MG \\
\hline++ & \# of bat roosts protected & 0 & 4 & KM \\
\hline++ & \# farms signed & 0 & 28 & $\mathrm{PE}$ \\
\hline+ & \# of initiatives & 0 & 1 & EC \\
\hline+ & \# organizations & 0 & 25 & $\mathrm{KM}$ \\
\hline \multirow{4}{*}{++} & \multirow{4}{*}{ Area $(\mathrm{Ha})$ conserved/restored } & 8530 & $\begin{array}{r}8583 . \\
36\end{array}$ & EC \\
\hline & & 0 & 500 & $\mathrm{KM}$ \\
\hline & & 310 & 354.7 & MG \\
\hline & & 0 & 49.5 & MU \\
\hline \multirow{4}{*}{+} & \multirow{4}{*}{ \# species recorded } & $\mathrm{nr}$ & 530 & $\mathrm{CO}$ \\
\hline & & $\mathrm{nr}$ & 622 & IN \\
\hline & & $\mathrm{nr}$ & 95 & MM \\
\hline & & $\mathrm{nr}$ & 20 & SC \\
\hline+ & \# individual primates recorded & $\mathrm{nr}$ & 33 & $\mathrm{PE}$ \\
\hline+ & \# individual bats recorded & $\mathrm{nr}$ & 696 & $\mathrm{KM}$ \\
\hline+ & \# villages covered & 0 & 3 & IN \\
\hline+ & \# fish spawning area protected & 0 & 19 & MM \\
\hline++ & $\%$ households trained & 0 & 22 & MG \\
\hline++ & Area $(\mathrm{Ha})$ certified & 0 & 6711 & $\mathrm{PE}$ \\
\hline++ & \# of organic products & 0 & 3 & $\mathrm{TH}$ \\
\hline++ & \# of groups involved & 0 & 35 & MU \\
\hline++ & $\%$ reduction of illegal fishing & 0 & 80 & MU \\
\hline++ & \# farms involved & 0 & 7 & $\mathrm{CO}$ \\
\hline+ & Area $(\mathrm{Ha})$ repopulated & 0 & 9 & EC \\
\hline+ & \# of organic products & 0 & 3 & $\mathrm{TH}$ \\
\hline+ & \# standards developed & 0 & 1 & $\mathrm{CO}$ \\
\hline++ & Area $(\mathrm{Ha})$ implemented & 0 & 150 & EC \\
\hline++ & $\mathrm{Kg} /$ year of quinoa produced & 0 & 13846 & PE \\
\hline+ & \# farmers trained & 0 & 2610 & KM \\
\hline++ & Ton/Ha of rice production & 1.5 & 3.7 & MG \\
\hline++ & $\%$ increased income & 0 & 30 & EC \\
\hline++ & $\mathrm{Kg} /$ year of honey produced & $\mathrm{nr}$ & 238.7 & $\mathrm{PE}$ \\
\hline+ & \# farms interviewed & 0 & 46 & $\mathrm{CO}$ \\
\hline++ & \# of producers & 0 & 1 & $\mathrm{CO}$ \\
\hline+ & \# people trained & 0 & 80 & TH \\
\hline+ & \# of tourist activities & 0 & 1 & $\mathrm{CO}$ \\
\hline+ & \# of tourist trails & 0 & 2 & IN \\
\hline+ & \# villages covered & 0 & 3 & $\mathrm{TH}$ \\
\hline \multirow{2}{*}{$\begin{array}{l}++ \\
++\end{array}$} & \multirow[b]{2}{*}{ \# species protected } & 0 & 13 & SC \\
\hline & & 0 & 1 & $\mathrm{TH}$ \\
\hline
\end{tabular}

NCP. 'Level' of indicators: + output; ++ outcome; +++ impact. 'nr' in the 'Value (ante)' column indicates 'not reported'. 'Project' column provides project codes. Refer to Table 1 for the full project titles. Also please see Supplementary Appendix 3 for the narratives on each project, describing the effect of different project interventions on NCP

landowners was an economic response that two projects adopted to safeguard threatened species habitat.

Physical and psychological experiences (NCP 16) were enhanced through technological responses, such as the development of tourism activities and trails in two projects. Participatory GIS mapping was a cognitive response used 
to lobby for statutory recognition of indigenous land use practices that constitute the identity (NCP 17) of indigenous peoples.

Individual projects implemented plural interventions which fell under two to six (on average 4.1) different response sub-categories. With a unique mix of these interventions contributing to different NCP, the individual projects enhanced a wide array of NCP.

\section{Discussion}

\section{NCP bundles in SEPLS}

The bundles of NCP, or the collection of different types of NCP attributed to the project SEPLS, were diverse, encompassing regulating, material and non-material NCP. The provision of food (NCP 12) and habitats (NCP 1), among other contributions, were the most common components of NCP bundles. The prominence of these two NCP could have derived from the scope of the request for project proposals and the project selection process by the GEF-Satoyama Project, which focused on sub-grant projects aiming to mainstream biodiversity into primary production sectors. Accordingly, all ten projects worked with local communities involved in primary production, particularly household farming, artisanal fishing, hunting and gathering. The variety of primary production types practiced by these communities was reflected in the array of ecosystems, not only limited to farmlands, that our study found provided food to people in the SEPLS. This is one of the major differences from the literature on ES bundles, which commonly attributes food provision to croplands (Raudsepp-Hearne et al. 2010; Maes et al. 2012; Turner et al. 2014; Yang et al. 2015; Renard et al. 2015; Dittrich et al. 2017). Our results suggest the importance of the different types of ecosystems constituting SEPLS in providing food and nutrition, and ultimately ensuring food security for people living in SEPLS. Habitat provision (NCP 1) also scored highly. This provision was attributed not only to natural forests but also production lands, including managed forest, freshwater, grasslands and coastal systems, underlining the importance of these production lands and waters in providing habitat for wildlife. The high score was possibly due to our scoring method, in which the scores assigned to important species were counted as the habitat provision NCP scores of the ecosystem type within which the species were found. We argue that this is a necessary weighting rather than a bias, as otherwise the importance of the role of ecosystems in providing habitat could not be sufficiently recognized (Rodríguez et al. 2006).

A wide array of regulating contributions from SEPLS was identified. These included water flow regulation (NCP 6), pollination and seed dispersal (NCP 2) and hazard regulation
(NCP 9), which were strongly attributed to natural forest, managed forest and coastal systems. Through these regulating contributions, the natural and semi-natural systems, which are often located on the periphery of SEPLS, stabilize the livelihood and security of people living in SEPLS alongside their direct role in providing food and other materials.

Our results also highlight the importance of the nonmaterial contributions that SEPLS offer, such as learning and inspiration (NCP 15), which often underlie the coproduction of several other NCP. In Thailand for example, the Karen youths learnt indigenous religious and livelihood practices in SEPLS, including rotational farming, from the elders. Such interactions across generations and between people and nature constitute a learning process that has enabled the co-production of crops and the safeguarding of water, soils and other NCP over generations. In this way, SEPLS clearly demonstrate the intention of NCP which is that it further expands the people and nature conceptual framework beyond a generalized perspective. This is achieved by including a context-specific perspective that recognizes unique local or cultural features with individual applicability to certain socio-ecological settings which cannot be transferred universally (Kadykalo et al. 2019; MartínLópez et al. 2019).

The multiplicity of NCP and their synergies within SEPLS as described above contrast to the literature on ES bundles that commonly depicts trade-offs between provisioning and other ES (Rodríguez et al. 2006; RaudseppHearne et al. 2010; Maes et al. 2012; Turner et al. 2014; Howe et al. 2014; Yang et al. 2015; Renard et al. 2015; Dittrich et al. 2017). The synergies between multiple NCP might partially explain the characteristics of NCP bundles in SEPLS but were possibly derived from methodological differences. We used the eighteen NCP reporting categories (Díaz et al. 2018) as cues to elicit the relative importance of different NCP derived from SEPLS in a comprehensive manner, including those which cannot be quantified. Most ES bundle studies identify from existing data the ES types that are quantifiable (Raudsepp-Hearne et al. 2010; Maes et al. 2012; Turner et al. 2014; Yang et al. 2015; Renard et al. 2015; Dittrich et al. 2017). Inevitably, this limits the type of ESs within the scope, and sometimes involves proxy variables of which the validity to represent specific ESs is yet to be sufficiently validated (Raudsepp-Hearne et al. 2010; Turner et al. 2014; Yang et al. 2015). We also note that our approach was not designed to critically assess the trade-offs between NCP as is often done in ES bundle studies (Raudsepp-Hearne et al. 2010; Maes et al. 2012; Turner et al. 2014; Yang et al. 2015; Renard et al. 2015; Dittrich et al. 2017). Trade-off analysis requires the quantity of NCP in absolute terms over time and spaces, which our study did not have. Therefore, whilst suggesting the potential synergies between a wide array of NCP in SEPLS, our results 
do not necessarily show the strength of such synergies or trade-offs compared to preceding studies.

\section{Options to enhance synergies among multiple NCP in SEPLS}

Our results suggest specific management options that are instrumental in enhancing or maintaining specific NCP, particularly food and habitat provision, and that make them compatible with other NCP. Packaging multiple management options, which aimed to enhance different NCP in the individual projects, generated synergistic NCP outcomes. The project outcomes pertaining to food and habitat were prominent in our results because, as we understand, these $\mathrm{NCP}$ were tangible and thus relatively easy to measure using indicators. Beyond these NCP, our results imply synergies in the NCP outcomes including those that are difficult to measure, particularly regulating contributions, e.g., pollination, seed dispersal and the regulation of freshwater flow, soil, climate and disasters, which mostly cascade down from the restoration or the safeguarding of habitat integrity (HainesYoung and Potschin 2010; Kandziora et al. 2013).

The management options focusing on food and livelihoods while ensuring compatibility with other NCP include organic agriculture, eco-labelling and branding, NTFP, improved agricultural practices and ecotourism. Organic agriculture generally restricts the use of synthetic fertilizers and pesticides which in turn reduces water eutrophication and biodiversity impacts (Tuomisto et al. 2012). Certification and branding can help improve the economic viability of organic agriculture and thus encourage its wider adoption (Qiao et al. 2015). NTFP such as forest honey production, improved agricultural practices and ecotourism can contribute to ecological integrity and help local communities improve their livelihoods if they are sustainably managed (Moegenburg and Levey 2002; Negi et al. 2011). These management options are instrumental in minimizing the tradeoffs between food and other NCP, as well as in addressing inequalities in conservation which tend to limit local communities' access to land and resources.

That most projects featured the food for livelihood improvement aspect is of particular significance. Besides the importance in diet (and therefore, the health) of people, food is an expression of cultural identity and pride (Pakagayo Association for Sustainable Development and Karen Network for Culture and Environment 2019). Associated activities included capacity building, improved subsistence food production without increasing the negative impacts on biodiversity (e.g., Madagascar, Comoros, Colombia, Myanmar), gaining a competitive advantage in the market by certification (Peru), and preserving a cultural identity (Thailand, India). In this way, food can be considered an effective entry point to attract and expand on the interest and engagement of local communities. Project interventions that focus on food target behavioural changes more clearly than many other interventions that focus on cognitive and attitudinal changes (Nilsson et al. 2020). Thus, the food-focused interventions are expected to be more effective in achieving better conservation outcomes.

Habitat-focused options that enhance synergies with other NCP include participatory biodiversity monitoring, habitat restoration, co-management and conservation agreement. Participatory biodiversity monitoring enlightens people's awareness of the value of species and their habitats. Habitat restoration generally improves several other NCP which cascade down from the restored ecosystem, particularly those regulating NCP (Kandziora et al. 2013). Restoration of highly productive ecosystems, such as mangrove restoration, combined with repopulation or natural feed aquaculture of species of high value on the seafood market, has the potential to increase food provision and local livelihoods alongside the improvement of other NCP. Fisheries co-management, including through the designation of fish conservation zones and the detailed measures to protect threatened fish species for artisanal fisheries, was instrumental in addressing trade-off in food provision (NCP 12) over time, and between food provision and the maintenance of options deriving from biodiversity below water (NCP 18). Conservation agreements with farmers, which secure their commitment to habitat protection on their lands and adjacent protected areas, combined with incentive measures such as technical support to improved agricultural practices, can enhance synergies between food production, habitat provision and the maintenance of future options.

Social, behavioural and cognitive responses that embrace multiple stakeholders and traditional knowledge are powerful tools in addressing inequalities in managing SEPLS, as well as in accessing the benefits accruing from those SEPLS. Community empowerment is central to these options, including capacity building and the establishment of inclusive CBOs that bring together people of different groups and sectors, thus reducing inequalities among them. Indigenous knowledge and practices are often an integral part of the social construct of SEPLS that have enabled harmonious interactions between people and nature for generations. Hence, documentation and effective use of such knowledge and practices in the modern context can ensure people's access to and sustainable co-production of NCP. Such an approach includes, among others, integration of indigenous knowledge and practices into organic agriculture and sustainable fisheries methods, as well as lobbying for their social recognition using participatory GIS mapping.

Good governance would provide an enabling framework upon which multiple management interventions targeting different NCP can be integrated and sustained 
for long periods, thereby generating synergies. The cases subject to this study accomplished this through mediation among different stakeholder groups including local communities, NGOs and academia, and by integrating knowledge systems associated with and gained through these interventions. All these initiatives emerged from the local level and worked with or were aligned to national- or subnational-level institutions to various extents (Table 3). Among these, five projects institutionalised mechanisms to link management responsibilities to higher levels of government, including co-management or conservation concession arrangements with national and sub-national governments. In such settings, a top-down prescription of institutional guidelines and management decisions integrated the knowledge generated and the partnerships formed through local implementations, providing a potential for scaling up the impacts. These rightly embody landscape approaches (Sayer et al. 2013), a governance concept to sustainably manage the lands and seas in which productive land uses compete with biodiversity. Nonetheless, there is no single code that applies to all, as all cases are embedded in unique governance opportunities and challenges. Therefore, it is imperative to take on a more nuanced perspective on top-down and bottom-up governance to administer shared learning from different interventions.

\section{Limitations and the way forward}

Our results show notable differences between the bundles of NCP that the project proponents identified as important for people in SEPLS (Fig. 3) and the sets of NCP enhanced or safeguarded by the project interventions (Fig. 4). Whilst these agree on the importance of habitat (NCP 1) and food
(NCP 12) provisions, the effects of the project interventions on other NCP that local people recognized as important, particularly regulating and non-material $\mathrm{NCP}$, were insufficiently captured in the project monitoring and evaluation frameworks. In theory, the cascading model suggests that enhanced habitat integrity improves regulating NCP (Haines-Young and Potschin 2010; Kandziora et al. 2013). Considering that SEPLS are important bio-cultural entities with which cultural and relational values are often interwoven, the enhancement of food and habitat provisions could simultaneously have enhanced non-material NCP, including learning, inspiration and identities.

The nature of the projects, which primarily aimed to enhance livelihoods, food production and environmental conservation most likely led to an emphasis on the selection of indicators of food and habitat. Also, the higher representation of food NCP by the selected indicators is consistent with the general preferences of human societies for more tangible NCP (Foley et al. 2005; Rodríguez et al. 2006). Indicators of regulating NCP were entirely absent. Quantifying changes in regulating NCP requires more intensive monitoring efforts and more time for effects to become visible than project funding sizes and durations allow. This could be the additional reason that these indicators were not used. The projects stipulated the indicators that relatively indirectly represented nonmaterial NCP. Such intangible aspects of NCP are not easily measurable (Satz et al. 2013) and thus tend to be embedded within more tangible project objectives.

The literature on ES bundles clarifies how NCP of different types can be quantified (Raudsepp-Hearne et al. 2010; Maes et al. 2012; Turner et al. 2014; Yang et al. 2015; Renard et al. 2015; Ament et al. 2017; Dittrich et al. 2017). Material contributions are commonly
Table 3 Different levels of institutions involved in the governance of the project sites

\begin{tabular}{lllll}
\hline Project & \multicolumn{2}{l}{ Level of institutions involved } & \multicolumn{2}{l}{ Mechanism to bridge institutions in different levels } \\
\cline { 2 - 4 } & National/state & Sub-national & Local & \\
\hline SC & ++ & & ++ & Co-management scheme \\
$\mathrm{MM}$ & ++ & & ++ & Co-management scheme \\
$\mathrm{MG}$ & + & ++ & ++ & Conservation concession, co-management scheme \\
$\mathrm{PE}$ & + & ++ & ++ & Conservation concession \\
$\mathrm{IN}$ & & ++ & ++ & Autonomous territory, co-management scheme \\
$\mathrm{KM}$ & + & & ++ & \\
$\mathrm{MU}$ & + & & ++ & \\
$\mathrm{CO}$ & + & & ++ & \\
$\mathrm{EC}$ & + & & ++ & \\
$\mathrm{TH}$ & + & & ++ & \\
\end{tabular}

Refer Table 1 for the project names. ++ the presence of an institution or an organization proactively involved in the governance of SEPLS at the respective levels. + the presence of an institution that provides an enabling framework for the governance of SEPLS. Please see Supplementary Appendix 3 for the narratives on each project about the governance structure 
measured by cropland coverage, material stock (e.g. livestock density and timber biomass volume) and production outputs. Modelling that draws on land use and land cover data is now commonly used to measure regulating NCP. Non-material NCP are quantified using relatively simple, proxy metrics. Such metrics of non-material NCP vary considerably with context, but tend to represent recreational uses of natural lands and seas relatively well.

The above suggests the utility of a more deliberate and balanced selection of indicators if the objective is to better understand the bundles of NCP in SEPLS and the effects of different management interventions on them. The indicators of material NCP adopted by the projects were consistent with those in the ES bundle literature. Acquisition of parameters necessary for modelling regulating NCP continues to be prohibitively demanding for community-based projects. Simple metrics suggested by local communities can be good substitutes, such as the extent and quality of woodland covering important watersheds, or mangrove areas that shelter coastal settlements from coastal hazards. Contextually appropriate proxies of non-material NCP in SEPLS could only come from people living in SEPLS. These include identifying and protecting the important areas that constitute their sense of place and cultural practices, as well as the number of people in different generations who inherit relevant traditional knowledge and practices. To legitimize such locally identified indicators of non-material NCP and thus to enable comparison across time and space, it would be beneficial to refer to the protocols on cultural ecosystem services indicators such as those proposed by HernándezMorcillo et al. (2013) and Hirons et al. (2016). Where the changes in NCP require long periods of time to appear after project interventions, their short-term proxies based on the logic model (Margoluis et al. 2009, 2013; Mascia et al. 2014) or the cascade model (Kandziora et al. 2013) could be used. Devising these indicators in landscape or seascape projects will help field practitioners learn to enhance synergies between NCP, and researchers and the broader conservation community can access untapped knowledge of NCP. More specifically, the identification of NCP bundles from local people's perspectives, if combined with mapping and modelling techniques, help us to better contextualise the analysis of NCP bundles.

\section{Conclusions}

With their landscape heterogeneity, SEPLS can generate synergies in NCP, particularly between habitat and food provisions, whereas the literature commonly reports trade-offs between these two provisions. The synergies can be enhanced by an integrated approach that combines food-centred and habitat-focused interventions, and is supported by an enabling governance structure and through community empowerment. The ambitious targets for expanding area-based conservation suggested in the development of the Post-2020 Global Biodiversity Framework necessitates accelerated efforts to bring appropriate management and conservation to production landscapes and seascapes. Of specific relevance is areas covered and proposed to be covered by the IUCN protected area categories V and VI, as well as of the OECMs, but attention should also be directed to broader areas of biodiversity importance. The management options and their mixed application for SEPLS as we outlined above will be instrumental in accelerating conservation efforts in such areas, and thereby can contribute to safeguarding biodiversity across the globe.

Supplementary Information The online version contains supplementary material available at https://doi.org/10.1007/s11625-021-00927-w.

Acknowledgements We thank the Global Environment Facility (GEF) for its support to the GEF-Satoyama project (Project ID: 5784). This research was also supported by the Environment Research and Technology Development Fund (S-15-1(4) Predicting and Assessing Natural Capital and Ecosystem Services (PANCES) of the Ministry of the Environment, Japan (JPMEERF16S11504). We thank the organizations which implemented the sub-grant projects (Table 1) for their generous cooperation to this research.

Open Access This article is licensed under a Creative Commons Attribution 4.0 International License, which permits use, sharing, adaptation, distribution and reproduction in any medium or format, as long as you give appropriate credit to the original author(s) and the source, provide a link to the Creative Commons licence, and indicate if changes were made. The images or other third party material in this article are included in the article's Creative Commons licence, unless indicated otherwise in a credit line to the material. If material is not included in the article's Creative Commons licence and your intended use is not permitted by statutory regulation or exceeds the permitted use, you will need to obtain permission directly from the copyright holder. To view a copy of this licence, visit http://creativecommons.org/licenses/by/4.0/.

\section{References}

Ament JM, Moore CA, Herbst M, Cumming GS (2017) Cultural ecosystem services in protected areas: understanding bundles, trade-offs, and synergies. Conserv Lett 10:440-450. https://doi. org/10.1111/conl.12283

CBD (2018) Scientific and technical advice on other effective areabased conservation measures. In: Decision 14/8. Protected areas and other effective area-based conservation measures. Convention on Biological Diversity, Sharm El-Sheikh, Egypt

OECD (2002) Glossary of key terms in evaluation and results based management. Development Assistance Committee Working Party on Aid Evaluation, Organisation for Economic Co-operation and Development, Paris

Darvill R, Lindo Z (2016) The inclusion of stakeholders and cultural ecosystem services in land management trade-off decisions 
using an ecosystem services approach. Landsc Ecol 31:533545. https://doi.org/10.1007/s10980-015-0260-y

Daw T, Brown K, Rosendo S, Pomeroy R (2011) Applying the ecosystem services concept to poverty alleviation: the need to disaggregate human well-being. Environ Conserv 38:370-379. https://doi.org/10.1017/S0376892911000506

Díaz S, Pascual U, Stenseke M et al (2018) Assessing nature's contributions to people. Science (80-) 359:270-272. https://doi. org/10.1126/science.aap 8826

Díaz S, Settele J, Brondízio ES et al (2019) Pervasive human-driven decline of life on Earth points to the need for transformative change. Science (80-) 366:eaax3100. https://doi.org/10.1126/ science. $\operatorname{aax} 3100$

Dittrich A, Seppelt R, Václavík T, Cord AF (2017) Integrating ecosystem service bundles and socio-environmental conditions-a national scale analysis from Germany. Ecosyst Serv 28:273-282

Dudley N (2008) Guidelines for applying protected area management categories. IUCN, Gland

Foley JA, DeFries R, Asner GP et al (2005) Global consequences of land use. Science (80-) 309:570-574

Haines-Young R, Potschin M (2010) The links between biodiversity, ecosystem services and human well-being. In: Raffaelli D, Frid C (eds) Ecosystem ecology: a new synthesis. Cambridge University Press, Cambridge, pp 110-139

Hermes J, Van Berkel D, Burkhard B et al (2018) Assessment and valuation of recreational ecosystem services of landscapes. Ecosyst Serv 31:289-295

Hernández-Morcillo M, Plieninger T, Bieling C (2013) An empirical review of cultural ecosystem service indicators. Ecol Indic 29:434-444

Hirons M, Comberti C, Dunford R (2016) Valuing cultural ecosystem services. Annu Rev Environ Resour 41:545-574. https://doi. org/10.1146/annurev-environ-110615-085831

Howe C, Suich H, Vira B, Mace GM (2014) Creating win-wins from trade-offs? Ecosystem services for human well-being: a meta-analysis of ecosystem service trade-offs and synergies in the real world. Glob Environ Change 28:263-275. https://doi. org/10.1016/j.gloenvcha.2014.07.005

IPBES (2019) Summary for policymakers of the global assessment report on biodiversity and ecosystem services of the Intergovernmental Science-Policy Platform on Biodiversity and Ecosystem Services. Díaz S, Settele J, Brondízio ES, Ngo HT, Guèze M, Agard J, Arneth A, Balvanera P, Brauman KA, Butchart SHM, Chan KMA, Garibaldi LA, Ichii K, Liu J, Subramanian SM, Midgley GF, Miloslavich P, Molnár Z, Obura D, Pfaff A, Polasky S, Purvis A, Razzaque J, Reyers B, Roy Chowdhury R, Shin YJ, Visseren-Hamakers IJ, Willis KJ, Zayas CN (eds) IPBES Secretariat, Bonn

IUCN (2020) IUCN Red List of Threatened Species. Version 2020-2. https://www.iucnredlist.org/. Accessed 13 Jul 2020

Kadykalo AN, López-Rodriguez MD, Ainscough J et al (2019) Disentangling 'ecosystem services' and 'nature's contributions to people.' Ecosyst People 15:269-287

Kandziora M, Burkhard B, Müller F (2013) Interactions of ecosystem properties, ecosystem integrity and ecosystem service indicators: a theoretical matrix exercise. Ecol Indic 28:54-78. https://doi. org/10.1016/j.ecolind.2012.09.006

MA (2005) Ecosystems and human well-being: policy responses, vol 3. Island Press, Washington

Maes J, Paracchini ML, Zulian G et al (2012) Synergies and tradeoffs between ecosystem service supply, biodiversity, and habitat conservation status in Europe. Biol Conserv 155:1-12. https://doi. org/10.1016/j.biocon.2012.06.016

Margoluis R, Stem C, Salafsky N, Brown M (2009) Using conceptual models as a planning and evaluation tool in conservation. Eval
Progr Plann 32:138-147. https://doi.org/10.1016/j.evalprogpl an.2008.09.007

Margoluis R, Stem C, Swaminathan V et al (2013) Results chains: a tool for conservation action design, management, and evaluation. Ecol Soc 18:10. https://doi.org/10.5751/ES-05610-180322

Martín-López B, Leister I, Cruz PL et al (2019) Nature's contributions to people in mountains: a review. PLoS ONE 14:e0217847. https ://doi.org/10.1371/journal.pone.0217847

Mauri M, Elli T, Caviglia G et al (2017) RAWGraphs: a visualisation platform to create open outputs. In: ACM international conference proceeding series. Association for Computing Machinery, New York, pp 1-5

Mascia MB, Pailler S, Thieme ML et al (2014) Commonalities and complementarities among approaches to conservation monitoring and evaluation. Biol Conserv 169:258-267

McShane TO, Hirsch PD, Trung TC et al (2011) Hard choices: making trade-offs between biodiversity conservation and human wellbeing. Biol Conserv 144:966-972. https://doi.org/10.1016/j.bioco n.2010.04.038

Millennium Ecosystem Assessment (2005) Ecosystems and human well-being: synthesis. Island Press, Washington

Moegenburg SM, Levey DJ (2002) Prospects for conserving biodiversity in Amazonian extractive reserves. Ecol Lett 5:320-324. https ://doi.org/10.1046/j.1461-0248.2002.00323.x

MOEJ, UNU-IAS (2010) Paris Declaration on the Satoyama initiative. Ministry of the Environment of Japan, United Nations University Institute of the Advanced Studies of Sustainability, Tokyo

Myers N, Mittermeier RA, Mittermeier CG et al (2000) Biodiversity hotspots for conservation priorities. Nature 403:853-858

Negi VS, Maikhuri RK, Rawat LS (2011) Non-timber forest products (NTFPs): a viable option for biodiversity conservation and livelihood enhancement in central Himalaya. Biodivers Conserv 20:545-559. https://doi.org/10.1007/s10531-010-9966-y

Nilsson D, Fielding K, Dean AJ (2020) Achieving conservation impact by shifting focus from human attitudes to behaviors. Conserv Biol 34:93-102. https://doi.org/10.1111/cobi.13363

Pakagayo Association for Sustainable Development, Karen Network for Culture and Environment (2019) Taj Auf Le Quv : cooking in the rotational farming. Sirindhorn Anthropology Center

Qiao Y, Halberg N, Vaheesan S, Scott S (2015) Assessing the social and economic benefits of organic and fair trade tea production for small-scale farmers in Asia: a comparative case study of China and Sri Lanka. Renew Agric Food Syst. https://doi.org/10.1017/ S1742170515000162

Raudsepp-Hearne C, Peterson GD, Bennett EM (2010) Ecosystem service bundles for analyzing tradeoffs in diverse landscapes. Proc Natl Acad Sci USA 107:5242-5247. https://doi.org/10.1073/ pnas.0907284107

Renard D, Rhemtull JM, Bennett EM (2015) Historical dynamics in ecosystem service bundles. Proc Natl Acad Sci USA 112:1341113416. https://doi.org/10.1073/pnas. 1502565112

Rodríguez JP, Douglas Beard T, Bennett EM et al (2006) Trade-offs across space, time, and ecosystem services. Ecol Soc 11:14

Santos-Martín F, Zorrilla-Miras P, García-Llorente M et al (2019) Identifying win-win situations in agricultural landscapes: an integrated ecosystem services assessment for Spain. Landsc Ecol 34:1789-1805. https://doi.org/10.1007/s10980-019-00852-5

Satz D, Gould RK, Chan KMA et al (2013) The challenges of incorporating cultural ecosystem services into environmental assessment. Ambio 42:675-684

Sayer J, Sunderland T, Ghazoul J et al (2013) Ten principles for a landscape approach to reconciling agriculture, conservation, and other competing land uses. Proc Natl Acad Sci 110:8349-8356. https://doi.org/10.1073/pnas.1210595110

SCBD (2020) Zero draft of the post-2020 global biodiversity framework appendices: preliminary draft monitoring framework for 
the goals and preliminary draft monitoring framework for targets. Conv. Biol. Divers. Open-ended Work. Gr. Post-2020 Glob. Biodivers. Framew

Tuomisto HL, Hodge ID, Riordan P, Macdonald DW (2012) Does organic farming reduce environmental impacts? —a meta-analysis of European research. J Environ Manag 112:309-320. https://doi. org/10.1016/j.jenvman.2012.08.018

Turner KG, Odgaard MV, Bøcher PK et al (2014) Bundling ecosystem services in Denmark: trade-offs and synergies in a cultural landscape. Landsc Urban Plan 125:89-104. https://doi.org/10.1016/j. landurbplan.2014.02.007
Yang G, Ge Y, Xue H et al (2015) Using ecosystem service bundles to detect trade-offs and synergies across urban-rural complexes. Landsc Urban Plan 136:110-121. https://doi.org/10.1016/j.landu rbplan.2014.12.006

Publisher's Note Springer Nature remains neutral with regard to jurisdictional claims in published maps and institutional affiliations. 